\title{
Medios noticiosos y audiencias: una exploración al consumo y a la credibilidad y confianza en estos durante la cuarentena por covid-19 en Colombia
}

\author{
News media outlets and audiences: an exploration of \\ consumption and their credibility and trust during the quarantine \\ by covid-19 in Colombia
}

Cobos, T. L. ${ }^{1}$

Recibido: 01-05-2021 - Aceptado: 15-08-2021

https://doi.org/10.26441/RC20.2-2021-A6

RESUMEN: Durante la cuarentena decretada por la pandemia de covid-19 en Colombia, se realizó una investigación exploratoria acerca de hábitos de consumo de medios noticiosos donde se abordó también la percepción de credibilidad y confianza en estos. Se aplicó una encuesta en línea entre abril y mayo de 2020 y participaron 2.084 personas de todo el país. Según los resultados, primó el consumo de redes sociales digitales, seguido de televisión tradicional (noticieros) y prensa digital; así como una muy baja credibilidad en general en los medios, y una percepción de confianza en los medios nacionales Canal 1 y El Tiempo.

Palabras clave: audiencias; medios noticiosos; confianza; credibilidad; covid-19; Colombia.

\begin{abstract}
During the quarantine decreed by the covid-19 pandemic in Colombia, an exploratory research was carried out on the consumption habits of the news media outlets, which also addressed the perception of credibility and trust in them. An online survey was administered between April and May 2020 and 2,084 people from all over the country participated. According to the results, the consumption of digital social networks, followed by traditional television (newscasts) and digital press prevailed; as well as a very low credibility in general in the news media outlets, and a perception of trust in the national media outlets Canal 1 and El Tiempo.
\end{abstract}

Keywords: audiences; news media outlets; credibility; trust, covid-19; Colombia.

\footnotetext{
1 Tania Lucía Cobos es Doctora en Comunicación y Periodismo por la Universitat Autònoma de Barcelona y Profesora Asistente del Programa de Comunicación Social de la Universidad Tecnológica de Bolívar (Colombia). tcobos@utb.edu.co, https://orcid.org/0000-0001-8348-3631
} 


\section{Introducción}

A finales de diciembre de 2019 agencias de noticias y medios noticiosos informaron que las autoridades de salud chinas estaban realizando una investigación a partir de la identificación de 27 casos de una extraña neumonía viral en la ciudad de Wuhan, provincia de Hubei, y que apuntaban a tener conexión con el virus causante del síndrome respiratorio agudo severo - SARS, mismo que entre 2002 y 2003 causó más de 700 fallecimientos (Reuters, 2019; AP, 2019). Un mes después, en enero de 2020, la Organización Mundial de la Salud - OMS declaró la emergencia de salud pública de interés internacional (en inglés PHEIC) por un nuevo coronavirus al que inicialmente se llamó 2019-nCoV y que había sido identificado como el causante de la referida situación en el país asiático en el que ya se habían confirmado 9.700 casos y otros 106 en 19 países (PAHO, 2020: 1; WHO, 2020a). En febrero del mismo, la OMS llamó covid-19, una contracción de coronavirus disease 2019, a la enfermedad causada por este patógeno al que el Comité Internacional de Taxonomía de Virus (ICTV en inglés) nombró como severe acute respiratory syndrome coronavirus 2 o SARSCoV-2 (PAHO, 2020: 1).

Este virus se caracteriza por ser altamente contagioso, pero con una baja tasa de letalidad (CCDC, 2020). Puede afectar a hombres y mujeres de cualquier edad, pero ser más severo en personas con enfermedades previas cardiovasculares, respiratorias, diabetes, entre otras, así como aquellos que superan los 60 años de edad tienen mayor probabilidad de fallecer (CCDC, 2020). Dependiendo de la severidad del caso, los supervivientes pueden experimentar una recuperación lenta o quedar con secuelas por tiempo indeterminado (Belluck, 2020). No todos los que se contagian enferman o si lo hacen, padecen la enfermedad sin mostrar ningún síntoma pudiendo algunos fallecer súbitamente, a estos se les conoce como asintomáticos (Kinnear, 2020) y se consideran impulsadores en la transmisión del virus (ConSalud, 2020). Si bien el SARS-CoV-2 se clasifica como un virus respiratorio ya que es su manifestación más usual, esta conceptualización se ha reorientando y se le considera como multisistémico dado que se ha detectado puede atacar también riñones, intestinos, vasos sanguíneos, cerebro, entre otros órganos, produciendo, por tanto, una variada sintomatología (Puelles et al, 2020; BBC, 2020).

A pesar de los crecientes casos detectados en diversos países y las voces de la comunidad científica internacional que sostenían que el mundo había entrado en pandemia, es decir, "la propagación mundial de una nueva enfermedad" (WHO, 2010), la OMS se resistió a declarar dicho estado pues "podría asustar aún más al mundo y provocar desesperación en algunos países. «Si no estamos convencidos de que es incontrolable, ¿por qué habríamos de llamarla pandemia?»" expresó Tedros Adhanom Ghebreyesus, director general de esta entidad (La Tercera, 2020). El 11 de marzo de 2020, la OMS anunció que se habían detectado más de 118.000 casos en 114 países y 4.291 personas habían perdido la vida a causa de la covid-19, por tanto, debido a "los alarmantes niveles de propagación y gravedad, como por los alarmantes niveles de inacción" se declaraba el estado de pandemia (WHO, 2020b). Estas acciones también le valieron a la OMS fuertes cuestionamientos y críticas por diversos gobiernos por su desempeño (Cobos, 2020: 37-38). Meses más tarde, tanto la OMS como la comunidad científica internacional manifestaron que existía la posibilidad de que la covid-19 pasara a ser endémica dadas las características de los coronavirus, las reinfecciones, la inmunidad desarrollada, los esquemas de vacunación y efectividad de las vacunas (Reuters, 2020a; Shaman y Galanti, 2020).

A 31 de diciembre de 2020 el estado de pandemia continuaba vigente y los conteos oficiales registraban más de 79 millones de casos confirmados, más de 1.7 millones de muertes y 223 países afectados (WHO, 2020c), mientras se avanzaba en el desarrollo de vacunas y gestión de jornadas de vacunación en algunas geografías del planeta (CincoDías, 2020a). 


\section{Marco teórico}

\subsection{La covid-19 en Colombia}

Para el caso particular de Colombia, el Ministerio de Salud y Protección Social (2020a) reportó el 6 de marzo de 2020 el primer caso de covid-19 en el territorio nacional detectado en una mujer de 19 años que había ingresado por Bogotá el previo 26 de febrero procedente de Italia, aunque una investigación posterior de la Universidad del Rosario et al. (2020) encontró que probablemente el primer caso llegó al país el 17 de febrero procedente de Francia. La primera muerte se registró el 16 de marzo de 2020 en Cartagena de Indias, un residente de 58 años con antecedentes de hipertensión y diabetes no tratados que fue contagiado por dos turistas italianos a quiénes había transportado en su taxi días antes (Ministerio de Salud y Protección Social, 2020b).

Ante estos sucesos mundiales y locales, la Presidencia de la República (2020a), a través del Decreto 457 de 2020, impuso el estado de aislamiento preventivo obligatorio o cuarentena a partir del 25 de marzo del mismo en todo el territorio nacional, aunque, semanas antes, alcaldes de Cartagena de Indias o Bogotá, por ejemplo, ya habían establecido toques de queda y medidas de aislamiento social dado los casos detectados en tales ciudades (Alcaldía Distrital de Cartagena de Indias, 2020; La República, 2020). Dicho estado de emergencia se fue prorrogando sucesivamente, desde el 1 de septiembre bajo el nombre de aislamiento selectivo con distanciamiento individual responsable según el Decreto 1168 de 2020 (Presidencia de la República, 2020b), flexibilizando también las medidas para reactivar paulatinamente, en unas regiones más que en otras, los servicios, la industria y el comercio. A 31 de diciembre de 2020 seguía vigente dicho estado y según datos del Ministerio de Salud y Protección Social (2020c), en el país se habían confirmado 1.642 .775 casos y de ellos 86.777 estaban activos, asimismo, se contabilizaban 43.213 fallecidos y 1.508 .419 recuperados, siendo los departamentos de Antioquia y Valle del Cauca los que más casos habían registrado (por encima de los cien mil) y en general más de 1.000 municipios afectados de los 1.122 establecidos en el país (Ministerio de Salud y Protección Social, 2020d).

\subsection{Medios de comunicación, noticias y crisis de salud pública}

De acuerdo a Lasswell y Wright (en Lozano, 1996: 46) una de las cuatro funciones de la comunicación de masas es la supervisión del entorno. Los medios de comunicación de masas, prensa, radio, televisión y ahora medios digitales, se dedican a la: "Recolección y distribución de información referente a los sucesos del ambiente de la sociedad en particular y de los más sobresalientes a nivel universal. Esta función permite a los integrantes de un grupo social orientar su propia acción de acuerdo con la manera como se vayan presentando los acontecimientos que ocurren en la sociedad [...] y este constante flujo de información [...] tiene consecuencias positivas: por ejemplo, el hecho de poner sobre aviso a la población en cuanto a amenazas y peligros inminentes (huracanes, ataques militares, epidemias, etc.)" (López, 1986: 93).

Lo anterior, tal como lo referencia Wright (1960 en De Moragas, 1986: 75) y Lozano (1996: 46), se corresponde, aproximadamente, con la producción y circulación de las noticias. De acuerdo a Potter (2006: 2-6), las noticias son información de interés general para una audiencia objetivo y, por tanto, los criterios de oportunidad, impacto, proximidad, controversia, prominencia, actualidad y extrañeza, a los que se les puede agregar novedad, desconocimiento y percepción de riesgo (Gómez, 2013: 41), determinan las mismas. En esa dirección, la covid-19, una enfermedad usualmente respiratoria, con una variada sintomatología, que puede ser asintomática, ligera, moderada o severa, causada por el SARS-CoV-2, un nuevo coronavirus de alta transmisibilidad que ha llevado a la declaración de pandemia, contra la cual se están ensayando vacunas y que ha afectado en mayor o menor medida los diferentes países y sus regiones, en efecto, cumple a cabalidad todos criterios mencionados, por 
tanto, llevará a los medios noticiosos a realizar un exhaustivo cubrimiento en lo sanitario, lo político, lo social, lo económico y lo cultural, generando así una agitación mediática de honda repercusión en la opinión pública dada la incertidumbre que representa, o como lo expresa Gómez (2013: 40) "si la sociedad siente miedo ante una hipotética amenaza, los medios de comunicación se volcarán en esa noticia y las repercusiones económicas, sanitarias, sociales y políticas serán notables".

Menciona Gómez (2013: 40) que "la mayor demanda de información se produce en el mayor momento de incertidumbre técnica", los gestores o responsables que atienden la crisis carecen de suficientes datos mientras que los medios de comunicación les apremian para que den explicaciones y soluciones. Lo anterior es evidente en el caso de la covid-19, como se referenció al inicio, los cables de Reuters y AP del 31 de diciembre de 2019 que mencionaban la situación en Wuhan y su posible conexión con el SARS, y teniendo en cuenta los antecedentes de este, fueron ampliamente replicados por los medios noticiosos en todo el mundo, incluyendo, desde luego, a Colombia. El estallido de la crisis puede ubicarse cuando quince días después, el 13 de enero de 2020, se confirmaba en Tailandia el primer caso de esta nueva enfermedad fuera de China (WHO, 2020d) y días después un caso en Japón, todos los infectados coincidían en haber estado Wuhan por lo que la OMS temía que el virus se estuviera esparciendo y envió a una advertencia a hospitales en todo el mundo (Reuters, 2020b). A partir de este momento, los medios noticiosos, y en el caso que nos interesa, los colombianos, se volcaron a cubrir cada aspecto relacionado con la covid-19, ubicando este tema en el top de su agenda mediática y con una variedad de framings o enfoques, aún más, como ya se mencionó, cuando se confirmó el 6 de marzo el primer caso en el país y diez días después, el 16 de marzo, el primer fallecimiento, y a partir de allí, las fuertes medidas tomadas por el Estado.

Pero, como indica Wright (1960 en De Moragas, 1986: 77), la comunicación de masas también tiene disfunciones (latentes y manifiestas) que se evidencian, entre otras, en los resultados de los cubrimientos periodísticos. Este autor coloca como ejemplo una campaña de salud pública que puede levantar la moral del personal sanitario al ver reconocido su trabajo, pero también asustar a ciertas personas y evitar que atiendan las instrucciones de estos. El cubrimiento constante de acontecimientos percibidos como negativos, como lo es una pandemia, dispara el consumo de noticias -instado por la necesidad de estar informado-, pero que también ocasiona en las audiencias angustia, ansiedad, pánico y apatía, lo que puede redundar en una disminución o incluso suspensión de este consumo por razones de salud mental.

\subsection{La credibilidad y confianza en los medios de comunicación y las noticias}

Ante el brote inicial y los posteriores rebrotes, las llamadas olas, los diferentes países alrededor del mundo han tomado fuertes medidas que han restringido la movilidad y forzado al confinamiento, siendo Colombia uno de estos. Estas han ocasionado que los ciudadanos pasen mucho más tiempo en casa, contribuyendo también a un incremento en la demanda de consumo de medios, y entre estos, de los noticiosos. Lo anterior, por tanto, también lleva a las audiencias a determinar los grados de credibilidad y confianza que otorgan a un determinado medio, así como también, a toda aquella información que circula en espacios como las redes sociales digitales y los servicios de mensajería instantánea. Tanto es así, que incluso la OMS alertó sobre la infodemia (WHO, 2020e), una sobreabundancia de información, algunas precisas otras no, que ocasiona que las personas tengan mayor dificultad para encontrar fuentes confiables y creíbles de las cuales guiarse.

Para efectos de este documento, sólo nos centraremos en el primero, la percepción de confianza y credibilidad de las audiencias respecto a los medios noticiosos que consumen. En este sentido, Ortiz y López (2002) afirman que existen tres indicadores que miden la percepción que tiene la opinión pública sobre los medios de comunicación de masas: el Índice de consumo de medios - ICM, el Nivel de credibilidad de los medios - NCM y el Índice de calificación de periodistas - ICP. Ahonda- 
remos en el ICM y NCM que interesan para este caso. Ortiz y López (2002) manifiestan que el ICM "evidencia a partir de una muestra representativa del universo de estudio, cuáles son los hábitos de consumo de medios entre televisión, radio, periódicos, revistas e internet. Este indicador está compuesto por la frecuencia con que las personas utilizan los medios y por las preferencias alternativas. Presenta además una escala de preferencia de las empresas informativas de cada uno de los respectivos medios confrontadas entre los ámbitos nacional, regional y local” (p. 11).

Por su parte el NCM "compuesto por la imparcialidad, la veracidad, confiabilidad, responsabilidad y claridad con que los medios transmiten la información a la opinión pública: [...] imparcialidad entendida como la acción de comunicar el todo de los hechos como se presentan, sin ocultar información que pueda desviar la percepción del público [...] veracidad, como un acto de ser de la verdad y es un elemento constitutivo imprescindible en la comunicación de los hechos [...] confiabilidad, es el acto de ser de la confianza en su acción mediadora [...] responsabilidad llama la atención sobre el impacto, bueno o malo, que produce la acciones de los medios en la sociedad [...] y claridad entendida como la pretensión de determinar un lenguaje común entre los medios de comunicación como mediadores y la sociedad, mismo que debe expresarse en criterios de universalidad, coherencia, exactitud y transparencia" (p. 13-14).

Las audiencias establecen sus propios parámetros de evaluación de los criterios anteriormente mencionados. En esa dirección, Masip et al. (2020: 3) apuntan, teniendo en cuenta el marco de la pandemia, que "el gran volumen de contenidos disponibles genera inseguridad acerca de la veracidad de la información que consumen", esto significa que las audiencias al contrastar las noticias que consumen sobre un mismo suceso en diversos medios y encontrar variedad de versiones de este, así como ser conscientes, en mayor o menor medida, de que los medios noticiosos tienen intereses políticos y sesgos ideológicos y que esto afecta el principio periodístico de la objetividad, se traduce en una pérdida de confianza en estos. De igual manera, como mencionan Masip et al. (2020:3), existe la crítica de que los medios noticiosos pueden generar alarmismo a partir de los enfoques o framings sensacionalistas con que, unos más que otros, realizan sus cubrimientos: "La cobertura sensacionalista de los medios puede llevar a distorsionar los hechos, proporcionando informaciones contradictorias y recomendaciones contraproducentes, tanto sobre la situación de la pandemia como de posibles medidas de prevención de la infección".

Aspectos de consumo, credibilidad y confianza han sido explorados en otras latitudes en el contexto de la pandemia. En España, por ejemplo, Masip et al. (2020) en "Consumo informativo y cobertura mediática durante el confinamiento por el covid-19: sobreinformación, sesgo ideológico y sensacionalismo" exploraron, entre otros aspectos, cómo percibían los ciudadanos la cobertura mediática realizada por los medios de comunicación. Encontraron que las audiencias mantuvieron una actitud crítica con la información que proporcionaron los medios y que estos últimos habían realizado una cobertura condicionada por la línea editorial, de forma sensacionalista y generando alarma social innecesaria. También Rodero (2020) en "La radio: el medio que mejor se comporta en las crisis. Hábitos de escucha, consumo y percepción de los oyentes de radio durante el confinamiento por el covid-19" abordó, entre otros aspectos, las percepciones que tenían los oyentes españoles de este medio en esta situación de crisis. "Para estos oyentes, la radio se posiciona como el medio que mejor está cubriendo la información sobre el coronavirus y el que consideran más creíble, más cercano, el que más estimula la imaginación, más distrae y más reduce la soledad". Por su parte Casero-Ripolles (2020) en "Impacto del covid-19 en el sistema de medios. Consecuencias comunicativas y democráticas del consumo de noticias durante el brote" abordó, entre otros aspectos, la credibilidad otorgada por los ciudadanos estadounidenses a los medios a partir de los datos del Pew Research Center's American Trends Panel, encontrando que había resurgimiento del protagonismo de los medios tradicionales como la televisión y la reconexión a las noticias de aquellas audiencias más alejadas de la información. 
En el marco de lo expuesto hasta aquí, esta investigación tuvo por objetivo explorar cuál fue el comportamiento de las audiencias colombianas con relación al consumo de medios de comunicación para mantenerse informadas sobre la pandemia por covid-19 durante las primeras semanas de la cuarentena en el país, así como identificar dentro del segmento de medios noticiosos colombianos, cuáles percibieron como confiables y creíbles.

\section{Método}

Este estudio hace parte de la investigación matriz "Consumo de medios de comunicación durante la pandemia de covid-19 en Colombia" del semillero de investigación Medios Masivos y Productos Culturales de la Universidad Tecnológica de Bolívar. El enfoque de esta fue cuantitativo y de alcance exploratorio y descriptivo dada la novedad del tema y la contingencia generada, así como la urgencia y premura por ejecutar los primeros diagnósticos de cómo estaba impactando la covid-19 en el ecosistema noticioso colombiano desde diversas perspectivas, entre ellas, el consumo de medios y la percepción de confianza y credibilidad que las audiencias estaban dando a los mismos.

Para tal fin se aplicó un cuestionario de 34 preguntas que recogió información sobre datos sociodemográficos, necesidad informativa, hábitos de consumo noticioso, credibilidad y confianza en medios, suscripciones, manejo de la desinformación, y memes. El cuestionario original fue diseñado por el Digilab: Media, Strategy and Regulation² de la Universitat Ramón Llul (España), el cual se adaptó al contexto colombiano. Dicho proceso de adaptación consistió en cambiar expresiones españolas por expresiones colombianas, verificando no alterar el sentido, para facilitar la comprensión del cuestionario, así como la modificación de algunas opciones de respuesta de acuerdo con la realidad colombiana.

El formulario se alojó en Microsoft Forms y estuvo abierto a respuestas desde el 4 de abril al 14 de mayo de 2020, es decir entre una semana después de iniciar el aislamiento social obligatorio o cuarentena en el país y pocos días después de su tercera extensión, siendo así, por tanto, una conformación a conveniencia de la muestra. Para la divulgación del mismo, se recurrió a distribuirlo a través de Facebook, Twitter, WhatsApp y correo electrónico con la intención de lograr la participación de las cinco regiones geográficas del país, incluyendo las que tienen muy baja conectividad. De acuerdo BBVA Research (2019) en Colombia se calculan 29 millones de usuarios de internet; los servicios más usados son Facebook y Whatsapp con más de 18 millones de usuarios, seguidos por YouTube con 9.9 millones, Instagram con 7 millones y Twitter con 4.1 millones, y existe una alta desigualdad en el acceso a internet según el nivel de ingreso y zona de ubicación.

El cuestionario barajó diversas opciones de respuestas: selección única, escogencia múltiple, escala de Likert, y en algunos casos la opción "otros". Al final de este había una respuesta abierta donde el encuestado o encuestada podía suministrar información adicional si lo deseaba. Todas las preguntas eran de respuesta obligatoria a excepción de la última, la de respuesta abierta, que era opcional. Los datos de las 2.084 respuestas obtenidas fueron exportados a Microsoft Excel para su análisis.

Como limitaciones, la muestra estuvo conformada sólo por personas que tenían acceso a internet y que fueron contactadas por alguna de las plataformas mencionadas, quedando por fuera, por tanto, aquellos que no cumplían tales condiciones. Asimismo, aunque se hizo un gran esfuerzo por obtener respuestas de personas residentes en departamentos del país con muy baja conectividad, la cantidad de respuestas recogidas fue muy baja, sin embargo, queda la satisfacción de que ninguno se quedó sin representación.

\footnotetext{
${ }^{2}$ La autora agradece a Pere Masip, PhD, quien como director de este centro, permitió el acceso al mencionado cuestionario. Paz en su tumba.
} 


\section{Resultados}

Como se indicó, participaron en total 2.084 personas con acceso a internet y residentes en alguna de las cinco regiones geográficas de Colombia, distribuidos así:

Tabla 1. Caracterización de la muestra

\begin{tabular}{|c|c|c|c|c|c|}
\hline Edad & Número & Porcentaje & Sexo & Número & Porcentaje \\
\hline De 17 o menos & 13 & $0.6 \%$ & Femenino & 1.065 & $51.1 \%$ \\
\hline De 18 a 24 años & 206 & $9.8 \%$ & Masculino & 1.019 & $48.8 \%$ \\
\hline De 25 a 34 años & 328 & $15.7 \%$ & Total & 2.084 & $100 \%$ \\
\hline De 35 a 44 años & 500 & $23.9 \%$ & & & \\
\hline De 45 a 54 años & 575 & $27.5 \%$ & & & \\
\hline De 55 a 64 años & 371 & $17.8 \%$ & & & \\
\hline De 65 años en adelante & 91 & $4.3 \%$ & & & \\
\hline Total & 2.084 & $100 \%$ & & & \\
\hline
\end{tabular}

Región geográfica

\begin{tabular}{|l|l|l|}
\hline $\begin{array}{l}\text { Región Andina } \\
\text { Departamentos: Antioquia (217), Boyacá (45), Caldas (53), Cundinamarca (291), Huila } \\
\text { (39), Norte de Santander (61), Quindío (38), Risaralda (44), Santander (93) y Tolima (44) }\end{array}$ & 925 & $44.3 \%$ \\
\hline $\begin{array}{l}\text { Costa Atlántica o Caribe } \\
\text { Departamentos: Atlántico (229), Bolívar (251), Cesar (28), Córdoba (42), Guajira (14), } \\
\text { Magdalena (34), San Andrés y Providencia (3) y Sucre (57) }\end{array}$ & 658 & $31.5 \%$ \\
\hline $\begin{array}{l}\text { Costa Pacífica } \\
\text { Departamentos: Chocó (5), Valle del Cauca (245), Cauca (59) y Nariño (50) }\end{array}$ & 359 & $17.2 \%$ \\
\hline $\begin{array}{l}\text { Orinoquia o Llanos Orientales } \\
\text { Departamentos: Arauca (14), Casanare (15), Meta (45) y Vichada (6) }\end{array}$ & 80 & $3.8 \%$ \\
\hline $\begin{array}{l}\text { Amazonía } \\
\text { Amazonas (2), Caquetá (17), Guainía (3), Guaviare (10), Putumayo (28) y Vaupés (2) }\end{array}$ & 62 & $2.9 \%$ \\
\hline Total & 2.084 & $100 \%$ \\
\hline
\end{tabular}

Fuente: Elaboración propia

En la Tabla 1 se aprecia que los rasgos destacables fueron: $51.1 \%$ féminas y $48.8 \%$ varones, en los rangos de edad de 45 a 54 años (27.5\%) y de 35 a 44 años (23.9\%), y ubicados principalmente en la Región Andina (44.3\%) seguido de la Costa Atlántica (31.5\%). Los departamentos con muy baja participación, de un dígito, se corresponden con los que tienen una conectividad muy baja, es decir, escasa cobertura y costoso servicio de conexión a internet (como Vaupés, Vichada, Amazonas y Guainía). Los de muy alta participación, tres dígitos, corresponden con la ubicación de las principales ciudades del país, por tanto, alta conectividad (Bogotá en Cundinamarca, Medellín en Antioquia, Santiago de Cali en el Valle del Cauca, Barranquilla en el Atlántico y Cartagena de Indias en Bolívar). Estos datos coinciden con las estadísticas del censo del Departamento Administrativo Nacional de Estadística - DANE (2018) en relación al acceso a internet.

Con relación al consumo de medios de comunicación para informarse sobre la pandemia de covid-19, se le indicó a los encuestados/as, de acuerdo a la lista que se les mostraba -que incluía masivos, sociales, e interpersonales-, que seleccionaran cuáles eran sus tres fuentes de información preferidas, señalándolas en el orden de cuál era la primera que consultaban, cuál de segunda y cuál de tercera: 
Tabla 2. Consumo por tipo de medio de comunicación

\begin{tabular}{|c|c|c|}
\hline \multicolumn{3}{|c|}{ ¿Cuál es el primer medio que usas para estar informado sobre la pandemia de covid-19? } \\
\hline Medio & Número & Porcentaje \\
\hline Redes sociales (Facebook, Twitter...) & 643 & $30.8 \%$ \\
\hline Periódicos por internet (tradicionales y nativos digitales) & 496 & $23.8 \%$ \\
\hline Televisión tradicional (noticieros, programas de opinión...) & 474 & $22.7 \%$ \\
\hline Radio tradicional (noticieros, programas de opinión...) & 167 & $8.0 \%$ \\
\hline Televisión por internet (noticieros, programas de opinión...) & 158 & $7.5 \%$ \\
\hline Radio por internet (noticieros, podcasts...) & 65 & $3.1 \%$ \\
\hline Mensajería instantánea (WhatsApp, Telegram...) & 31 & $1.4 \%$ \\
\hline Periódicos impresos & 13 & $0.6 \%$ \\
\hline Otras & 27 & $1.6 \%$ \\
\hline No lo sé & 1 & $0.04 \%$ \\
\hline Prefiero no contestar & 9 & $0.4 \%$ \\
\hline TOTAL & 2.084 & $100 \%$ \\
\hline \multicolumn{3}{|l|}{ ¿Cuál es el segundo medio? } \\
\hline Redes sociales (Facebook, Twitter...) & 565 & $27.1 \%$ \\
\hline Televisión tradicional (noticieros, programas de opinión...) & 547 & $26.2 \%$ \\
\hline Periódicos por internet (tradicionales y nativos digitales) & 357 & $17.1 \%$ \\
\hline Radio tradicional (noticieros, programas de opinión...) & 182 & $8.7 \%$ \\
\hline Televisión por internet (noticieros, programas de opinión...) & 159 & $7.6 \%$ \\
\hline Mensajería instantánea (WhatsApp, Telegram...) & 110 & $5.2 \%$ \\
\hline Radio por internet (noticieros, podcasts...) & 73 & $3.5 \%$ \\
\hline Periódicos impresos & 40 & $1.9 \%$ \\
\hline Otras & 18 & $1.2 \%$ \\
\hline No lo sé & 10 & $0.4 \%$ \\
\hline Prefiero no contestar & 23 & $1.1 \%$ \\
\hline TOTAL & 2.084 & $100 \%$ \\
\hline \multicolumn{3}{|l|}{ ¿Y cuál es el tercer medio? } \\
\hline Redes sociales (Facebook, Twitter...) & 506 & $24.2 \%$ \\
\hline Mensajería instantánea (WhatsApp, Telegram...) & 335 & $16 \%$ \\
\hline Televisión tradicional (noticieros, programas de opinión...) & 333 & $15.9 \%$ \\
\hline Periódicos por internet (tradicionales y nativos digitales) & 240 & $11.5 \%$ \\
\hline Televisión por internet (noticieros, programas de opinión...) & 170 & $8.1 \%$ \\
\hline Radio tradicional (noticieros, programas de opinión...) & 165 & $7.9 \%$ \\
\hline Radio por internet (noticieros, podcasts...) & 91 & $4.3 \%$ \\
\hline Periódicos impresos & 62 & $2.9 \%$ \\
\hline Otras & 28 & $1.3 \%$ \\
\hline No lo sé & 89 & $4.2 \%$ \\
\hline Prefiero no contestar & 65 & $3.1 \%$ \\
\hline TOTAL & 2.084 & $100 \%$ \\
\hline
\end{tabular}

Fuente: Elaboración propia

En la Tabla 2 se aprecian varios hallazgos. En primera instancia, las redes sociales digitales (Facebook, Twitter...) se ubicaron de primeras, $30.8 \%, 27.1 \%$ y $24.2 \%$, por encima de los medios noticiosos. Estas no son productoras de información de actualidad sino plataformas distribuidoras 
de información, incluyendo las noticias de los medios de comunicación internacionales, nacionales, regionales y locales. Dado que el consumo se dio en confinamiento, queda en evidencia que las mismas, además de fuente de entretenimiento, también fueron la principal fuente de información sobre la pandemia.

En segunda instancia, se aprecia que en las segundas opciones se ubicaron la televisión tradicional (noticieros, programas de opinión...) con $26.2 \%$, seguido de los periódicos por internet (tradicionales y nativos digitales) con $23.8 \%$ y la mensajería instantánea (WhatsApp, Telegram...) con $16 \%$. Por tanto, la televisión tradicional, que evidencia un fuerte repunte en índices de audiencia, y la prensa digital fueron los principales medios noticiosos consumidos en esta etapa de la cuarentena. Por último, se ubicaron las plataformas digitales de comunicación interpersonal instantánea dado su uso para compartir o recibir, entre otros, contenidos noticiosos a otros contactos o a grupos.

En tercera instancia, en lugares intermedios, en las tres opciones se ubicaron la radio tradicional $(8 \%, 8.7 \%, 7.9 \%)$, la televisión por internet $(7.5 \%, 7.6 \%, 8.1 \%)$ y la radio por internet $(3.1 \%, 3.5 \%$, $4.3 \%)$. En última instancia, se aprecia que los periódicos impresos fueron los medios escasamente consumidos al ubicarse de último en las tres opciones, $0.6 \%, 1.9 \%, 2.9 \%$, lo que los deja como los más perjudicados en esta dinámica en cuarentena.

Posterior a esto, a las audiencias se les preguntó, como una forma de sondear la confianza en estos, si consideraban que los medios de comunicación estaban informando correctamente sobre la pandemia de covid-19:

Tabla 3. Valoración de las fuentes informativas

\begin{tabular}{|c|c|c|}
\hline \multicolumn{3}{|c|}{$\begin{array}{l}\text { ¿Considero en general que los medios de comunicación están } \\
\text { informando correctamente sobre la pandemia de covid-19? }\end{array}$} \\
\hline & Número & Porcentaje \\
\hline Totalmente en desacuerdo & 335 & $16 \%$ \\
\hline En desacuerdo & 645 & $30.9 \%$ \\
\hline Ni de acuerdo, ni en desacuerdo & 648 & $31 \%$ \\
\hline De acuerdo & 405 & $19.4 \%$ \\
\hline Totalmente de acuerdo & 51 & $2.4 \%$ \\
\hline TOTAL & 2.084 & $100 \%$ \\
\hline
\end{tabular}

Fuente: Elaboración propia

En la Tabla 3 se aprecia una particular situación con relación a la valoración que dieron las audiencias encuestadas. E1 31\% (648) optó por una posición neutral, que puede interpretarse como "no lo sé", "no tengo una opinión" o "no quiero responder", y el 30.9\% (645) en desacuerdo, por tanto, el $62 \%$ de la muestra se ubicó de forma equitativa en estas dos posiciones distintas entre ellas. De manera agregada, encontramos que el 47\% (980) asumió una posición de disconformidad, el 31\% (648) una posición neutral y el 21.8\% (456) una posición de conformidad. Siendo así, en términos generales, se evidencia que las audiencias encuestadas consideran que los medios de comunicación no estaban informando correctamente sobre este suceso, lo que evidenciaría una falta de confianza, aunque no como rasgo dominante.

Seguidamente, a las audiencias se les preguntó a cuál fuente le otorgaban mayor credibilidad cuando se informaban sobre la pandemia: 
Tabla 4. Credibilidad en las fuentes informativas

\begin{tabular}{|l|c|c|}
\hline ¿A qué fuente otorgas mayor credibilidad cuando informa sobre la pandemia de covid-19? \\
\hline Fuente & Número & Porcentaje \\
\hline Personal sanitario y científicos & 1.224 & $58.7 \%$ \\
\hline Administraciones públicas (alcaldía, gobernación, presidencia, secretarías, ministerios) & 627 & $30 \%$ \\
\hline Medios de comunicación & 141 & $6.7 \%$ \\
\hline Ciudadanos "normales" en redes sociales & 38 & $1.8 \%$ \\
\hline Expertos económicos & 29 & $1.3 \%$ \\
\hline Conciudadanos, amigos y familiares & 17 & $0.8 \%$ \\
\hline Influencers & 7 & $0.3 \%$ \\
\hline Partidos políticos & 1 & $0.04 \%$ \\
\hline TOTAL & 2.084 & $100 \%$ \\
\hline
\end{tabular}

Fuente: Elaboración propia

En la Tabla 4 se aprecia que más de la mitad de los colombianos encuestados/as, 58.7\% (1.224), afirmaron otorgarle credibilidad al personal sanitario y científico en primer lugar, seguido de lejos, en un segundo lugar, a la administración pública con un 30\% (627). Los medios de comunicación se ubicaron en un lejano tercer lugar con apenas el 6.7\% (141). Resulta llamativo que, como se apreció en la Tabla 2, los medios de comunicación televisión tradicional y prensa digital fueron los más utilizados para informarse sobre la pandemia, pero en una valoración general en comparación con otras formas de información, las audiencias manifestaron que estos no estaban informando correctamente (ver Tabla 3), así como también les otorgaron una muy baja credibilidad que quedó evidenciada en los comentarios: Hay "mucho amarillismo y poca confiabilidad en los datos" (fémina, 55 a 64 años, Atlántico), “[...] Hay poco análisis y rigor a la hora de cubrir la pandemia en noticieros" (varón, 35 a 44 años, Valle del Cauca), "Algunos medios de comunicación transmiten con mucha intensidad horaria las noticias relacionadas con el virus" (fémina, 25 a 34 años, Bolívar).

Finalmente, se le pidió a las audiencias que, de los medios de comunicación colombianos que se les mostraba, escogieran los tres que consideraban más merecedores de confianza para informarse sobre el tema. Aquí tenían la opción de incluir otros que no se listaban. En total fueron mencionados 64 entre internet, televisión, radio y prensa, así como nacionales, regionales y locales:

Tabla 5. Top 15 de medios de comunicación percibidos como más confiables

\begin{tabular}{|c|c|c|c|c|c|}
\hline Orden & Nombre del medio & Tipo & Cubrimiento & Número & Porcentaje \\
\hline 1 & Canal 1 & Televisión & Nacional & 866 & $41.5 \%$ \\
\hline 2 & El Tiempo & Periódico & Nacional & 752 & $36 \%$ \\
\hline 3 & El Espectador & Periódico & Nacional & 679 & $32.5 \%$ \\
\hline 4 & Caracol Televisión & Televisión & Nacional & 608 & $29.1 \%$ \\
\hline 5 & City TV & Televisión & Regional & 377 & $18 \%$ \\
\hline 6 & Revista Semana & Revista & Nacional & 316 & $15.1 \%$ \\
\hline 7 & RCN Televisión & Televisión & Nacional & 306 & $14.6 \%$ \\
\hline 8 & El Heraldo & Periódico & Regional & 217 & $10.4 \%$ \\
\hline 9 & Señal Colombia & Televisión & Nacional & 200 & $9.5 \%$ \\
\hline 10 & Caracol Radio & Radio & Nacional & 185 & $8.8 \%$ \\
\hline
\end{tabular}




\begin{tabular}{|r|l|l|l|r|c|}
\hline 11 & El País & Periódico & Regional & 178 & $8.5 \%$ \\
\hline 12 & El Colombiano & Periódico & Regional & 160 & $7.6 \%$ \\
\hline 13 & Canal Institucional & Televisión & Nacional & 150 & $7.1 \%$ \\
\hline 14 & Teleantioquia & Televisión & Regional & 139 & $6.6 \%$ \\
\hline 15 & RCN Radio & Racional & 137 & $6.5 \%$ \\
\hline $16-64$ & Otros 49 medios de comunicación & 519 & $23.6 \%$ \\
\hline \multicolumn{2}{|l|}{} & & 45 & $2.1 \%$ \\
\hline
\end{tabular}

Fuente: Elaboración propia

En una mirada general a la Tabla 5, se aprecia que en el Top 15 de los medios de comunicación colombianos más merecedores de confianza para informarse sobre la covid-19, se ubicaron medios tradicionales, muy conocidos y de larga trayectoria, distribuidos en siete canales de televisión, cinco periódicos, dos cadenas de radio y una revista. Los dos primeros confirman lo explicitado en la Tabla 2, la televisión tradicional (noticieros, programas de opinión...) y el periódico (digital), fueron los medios noticiosos más consumidos. Asimismo, diez de estos medios eran de cubrimiento nacional y los cinco restantes de cubrimiento regional.

En el primer lugar se ubicó el Canal 1 con el 41.5\%. Este es un canal televisión tradicional abierta, de cubrimiento nacional y de carácter público-privado ${ }^{3}$ que emite desde Bogotá el noticiero NotiCentro $1 C M \&$ dos veces al día (primera y central), en cuyo sitio web https://noticias.canall.com. $\mathrm{co} /$ publican noticias y hay acceso bajo demanda sin costo a los videos de las emisiones pasadas. En la emisión central incluye el espacio editorial "Pregunta Yamid", con Yamid Amat, periodista director de este. La señal del canal puede también sintonizarse online desde el sitio web del canal, que incluye, desde luego, las emisiones del noticiero.

Canal 1 es promocionado como una opción adicional a los canales privados en el país como son Caracol Televisión y RCN Televisión (El Economista, 2016), llama por tanto la atención que estos dos canales, que emiten los noticieros Noticias Caracol y Noticias $R C N$ respectivamente y otros programas de opinión, a pesar de ser los dominantes, hayan quedado en posiciones inferiores: en cuarto lugar Caracol Televisión con 29.1\% (608) y en séptimo lugar RCN Televisión con 14.6\% (306). Los comentarios dejados dan un atisbo a el por qué de esto: "Los canales nacionales $R C N$ y Caracol no son recomendables a la hora de informar" (varón, 25 a 34 años, Caquetá), "Tomo el medio de noticias más a la mano, Caracol Noticias, pero me apego a lo más relevante porque no confío mucho en ellos" (varón, 18 a 24 años, Caldas), "[...] considero excesiva, manipulada y muy sesgada la información que emiten los medios televisivos tradicionales como Caracol y RCN [...]" (varón, 45 a 53 años, Sucre) y "He dejado de consumir noticieros de TV abierta, Caracol y $R C N$, los he cambiado por Noticias Uno, Canal 13, y noticieros locales” (varón, 25 a 34 años, Norte de Santander).

En segundo lugar se ubicó El Tiempo con un 36\%. Este es un periódico tradicional de impresión diaria y de cubrimiento nacional con sede en Bogotá, y con versión digital en ElTiempo.com, que se actualiza con frecuencia y que explota los recursos multimedia. Este es el principal diario del país, propiedad de la Casa Editorial El Tiempo (a su vez de la Organización Luis Carlos Sarmiento Angulo). Un aspecto interesante es que lanzó un modelo de suscripción paga o paywall para su versión digital en octubre de 2020 (Celedón, 2020).

\footnotetext{
${ }^{3}$ Le pertenece al Estado colombiano, pero es administrado por Plural Comunicaciones, un consorcio privado integrado por RTI (Radio Televisión Interamericana), CM\& (Compañía de Medios de Información), NTC (Nacional de Televisión y Comunicaciones), y la estadounidense HMTV1 (Hemisphere Media Group, Inc.).
} 
A medida que la lista desciende, aparecieron medios de cubrimiento regional y local como Telepacifico (televisión) 4.3\%, Vanguardia Liberal (periódico) 2.5\% o Emisora Atlántico (0.04\%); así como medios nativos digitales, como por ejemplo, Las 2 Orillas (prensa digital) $0.2 \%$ o La Retórica $C T G$ (televisión) $0.04 \%$. Finalmente, un 2.1\% (45) manifestó que ningún medio de comunicación colombiano era merecedor de confianza para informarse sobre la covid-19.

\section{Discusión y conclusiones}

A finales de diciembre de 2020, un año después de los cables que advertían la situación en Wuhan (China), la pandemia seguía vigente y más aguda en unos países que en otros, y dentro de estos, en unas regiones más que en otras, y por tanto, la continuidad de medidas que restringían la movilidad y de autocuidado, y la divulgación diaria de estadísticas sobre casos activos, recuperados y fallecidos. También, la aprobación exprés de algunos gobiernos de vacunas experimentales con permiso de uso de emergencia de la OMS que no evitarían el contagio, pero prometían disminuir la posibilidad de una covid-19 moderada o severa (Noticias ONU, 2020). Este panorama, por tanto, sigue estimulando la producción de noticias, así como la necesidad de las audiencias de seguir informadas, en particular, en las olas o picos, nuevos hallazgos sobre la enfermedad y otros relacionados, así como la valoración constante de la credibilidad y confianza en los medios de comunicación.

En este estudio se evidenció que las audiencias colombianas encuestadas durante los primeros períodos del aislamiento preventivo obligatorio o cuarentena, utilizaron, de forma preponderante -primera, segunda y tercera opción- las redes sociales digitales (Facebook, Twitter, Instagram, YouTube...) como medio para informarse sobre la pandemia. Esto también es un indicador de la alta exposición que tuvieron a la desinformación y bulos que circulan por estas (Cobos, 2020), así como a las noticias que los mismos medios distribuyen en estas (y también las audiencias), contribuyendo ambas a la infodemia, y al reforzamiento de tales plataformas como grandes concentradores de audiencias, que a su vez redunda en un incremento en su facturación por publicidad. A julio de 2020, Facebook, la que mayor número de usuarios ostenta, anunció que sus ganancias durante el primer semestre se habían incrementado un $11 \%$ con respecto a este mismo periodo en el 2019 , las medidas de confinamiento impuestas en gran parte del mundo, en la que se incluye Colombia, ayudaron a que esta red social digital atrajera más usuarios y los usuarios activos se incrementaran en un $12 \%$ con respecto al año anterior (Cinco Días, 2020b).

Los medios de comunicación como la televisión tradicional y la prensa digital fueron los segundos utilizados para informarse sobre este tema, implicando para el primero un repunte en audiencia, misma que había venido perdiendo paulatinamente en los últimos años ante los medios sociales y ante la televisión en streaming y bajo demanda. Este incremento, estimulado por el confinamiento que significó mayor tiempo en casa y la necesidad de estar informados, podría haber tenido algún efecto positivo en la inversión de pauta publicitaria que reciben. Según Kantar Ibope Media (en Eje21, 2020), única empresa que mide el rating y consumo de televisión en Colombia, el consumo de televisión en el 2020 fue más alto que en el 2019: "mientras que en agosto de 2019 los colombianos veían un promedio de 4 horas 14 minutos, en ese mismo periodo de este año ven 4 horas 41 minutos, es decir 27 minutos más de televisión. Y si nos referimos al pico que se tuvo durante la pandemia los colombianos alcanzaron a ver 1 hora y 3 minutos más en el mes de abril comparado con el mismo mes del año pasado" y "a pesar de que el consumo de televisión se ha normalizado en los últimos meses luego del confinamiento obligatorio, su consumo comparado con el año pasado

sigue siendo más alto". Finalmente, los noticieros estaban entre los géneros de televisión más vistos por las audiencias colombianas en agosto de 2020 y los contenidos no comercializables, entre los que se cuenta programas "gubernamentales y de contenido sobre covid-19 son cada vez menos vistos, aunque durante los primeros meses de la pandemia en Colombia aumentaron 300\%”. 
El gran perdedor fue el periódico impreso que experimentó una fuerte caída en su demanda, sin poderse determinar su magnitud, dado quizás por la restricción de movilidad o por su "lentitud" (de un día para otro) para satisfacer la necesidad de información y, por tanto, se reforzó la progresiva pérdida de audiencia que venía desde ante de la pandemia, y con ello, caída en la inversión publicitaria. Esto significó un impacto negativo a las finanzas de sus casas editoriales dado que la pérdida de audiencia significa disminución de anunciantes, de venta de ejemplares y probablemente de nuevas suscripciones, pero, en paralelo, aceleró el lanzamiento de suscripciones de pago o paywalls en sus versiones digitales, tal como lo hicieron entre septiembre y diciembre de 2020 los medios nacionales El Tiempo -eltiempo.com- y la revista Semana -semana.com- (Celedón, 2020) y el medio regional El Heraldo -elheraldo.co- (E1 Heraldo, 2020), para monetizar así la fuerte demanda digital de información noticiosa y que, como se reseñó previamente, la prensa digital es una de las más consultadas para la satisfacción de la misma. Como una aproximación inicial, en esta investigación se le preguntó a las audiencias si se habían suscrito a algún medio informativo digital durante la cuarentena, sea porque hubiese pagado o porque se le pedía registrarse para acceder, un $13 \%(272)$ respondió que sí lo habían hecho y un $84.4 \%$ (1.759) que no. Los restantes no lo sabían, $1.80 \%$ (38) o preferían no responder $0.70 \%$ (15). Este aspecto es interesante para investigaciones posteriores en el ecosistema noticioso colombiano digital.

En cuanto a la confianza, desde la perspectiva de valoración si los medios de comunicación estaban haciendo correctamente su trabajo, se evidenció una posición con tendencia a la disconformidad, y en cuanto a la credibilidad, las audiencias colombianas encuestadas otorgaron un valor muy bajo a los medios de comunicación. Ambos aspectos se explicarían a partir de las variables ya expuestas: sesgos ideológicos, intereses políticos de los medios, infodemia noticiosa y cubrimientos sensacionalistas o amarillistas, que quedaron visibilizadas también en la opción de comentarios adicionales, y un valor muy alto al personal sanitario y científico, y a la administración pública, que no deja de ser paradójico, los medios para producir sus noticias con relación a la pandemia de covid-19 recurren, en menor medida, a las primeras como fuentes no oficiales, y en mayor medida, a las segundas como fuentes oficiales, que, sin embargo, a nivel de impacto en la audiencia, las "noticias sobre información médica relacionada al covid-19 presentan mayor efecto que aquellas noticias con marcos no médicos" (Sotelo, 2020: 145).

Por último, las audiencias encuestadas consideraron que los medios tradicionales, muy conocidos y de larga trayectoria, particularmente prensa digital y televisión, eran los más merecedores de confianza para informarse sobre la covid-19, ubicando en primer lugar al canal de televisión tradicional Canal 1 -que emite el noticiero NotiCentro $1 C M \&$-, seguido por el periódico digital El Tiempo. Con respecto al primero, se plantea una duda razonable que surgió a partir de la revisión de los comentarios adicionales donde varios señalaban confiar en Noticias Uno, noticiero que se emite por el canal Cablenoticias. La duda está en que si algunos de los encuestados/as pudieron eventualmente haber confundido los nombres Canal 1 con Noticias Uno o asociarlos erróneamente.

Para cerrar, lo dicho anteriormente lleva a dejar los siguientes aspectos planteados. Primero, la necesidad de hacer investigaciones posteriores que aborden enfoque of framing de los contenidos relacionados con la covid-19, en particular los noticiosos televisivos, en búsqueda de identificar los elementos a partir de los cuáles las audiencias comentaron sus percepciones negativas, especialmente sobre los canales nacionales $R C N$ y Caracol, así como identificar las buenas prácticas de aquellos que tuvieron una buena percepción en estos como Noticias Uno. En este sentido también, se sugiere una investigación posterior que indague si estas percepciones se extienden a las franquicias radiales de estas empresas, es decir, Caracol Radio y RCN Radio, mismas que se ubicaron en puestos inferiores a sus pares televisivos dentro del Top 15 de medios colombianos merecedores de confianza. Asimismo, se sugiere otra en que se profundice sobre las preferencias de consumo de noticieros colombianos en tiempo de pandemia que permita esclarecer si puede haber confusión o asociación 
errónea en las audiencias entre Canal 1 y Noticias Uno. Segundo, desde la figura de la defensoría de audiencia (Ej: Defensor del Televidente, Defensor del Lector), los medios de comunicación colombianos deberían realizar una autoevaluación de los contenidos noticiosos y de otra naturaleza que están emitiendo / transmitiendo / publicando relacionados con la pandemia de covid-19 en aras de mejorar la calidad de los cubrimientos y disminuir las percepciones negativas que se hallaron aquí.

\section{Bibliografía}

Alcaldía Distrital de Cartagena de Indias (2020, marzo 13). Decreto 0495 por el cual se adoptan medidas y acciones sanitarias en el Distrito de Cartagena con ocasión de la declaración de emergencia sanitaria por causa del Coronavirus (covid-19). https://bit.ly/3loo15b

Associated Press - AP (2019, diciembre 31). China investigates respiratory illness outbreak sickening 27. https://apnews.com/00c78d1974410d96fe031f67edbd86ec

BBVA Research (2019). Uso de la tecnología en el día a día de la economía colombiana. https:// www.bbvaresearch.com/publicaciones/uso-de-la-tecnologia-en-el-dia-a-dia-de-la-economiacolombiana/

BBC (2020, mayo 25). Coronavirus | De enfermedad respiratoria a multisistémica: cómo en pocas semanas cambió radicalmente lo que sabemos sobre la covid-19. https://www.bbc.com/ mundo/noticias-52793269

Belluck, P. (2020, julio 2). Así es la recuperación para muchos de los sobrevivientes de la covid-19. The New York Times. https://www.nytimes.com/es/2020/07/02/espanol/ciencia-ytecnologia/sobrevivientes-coronavirus-recuperacion.html

CCDC (2020). Vital surveillances: the epidemiological characteristics of an outbreak of 2019 novel coronavirus diseases (Covid-19) - China, 2020. China CDC Weekly, 2 (8), 113-122. http:// dx.doi.org/10.46234/ccdcw2020.032

Casero-Ripolles, A. (2020). Impacto del covid-19 en el sistema de medios. Consecuencias comunicativas y democráticas del consumo de noticias durante el brote. El profesional de la información, 29(2), 1-12. https://doi.org/10.3145/epi.2020.mar.23

Celedón, N. (2020, octubre 23). El Tiempo y Semana se suman al salto mortal de las suscripciones digitales. La Silla Vacía. https://lasillavacia.com/tiempo-y-semana-se-suman-al-salto-mortal-lassuscripciones-digitales-78894

CincoDías (2020a, diciembre 4). Calendario de la vacuna del covid 19: ¿cuándo me la pondrán? https://cincodias.elpais.com/cincodias/2020/12/01/economia/1606824892_881234.html

CincoDías, (2020b, julio 30). Facebook sube sus ingresos un 11\% y gana un 98\% más a pesar del boicot publicitario. https://cincodias.elpais.com/cincodias/2020/07/30/ companias/1596144432_330044.html

Cobos, T. (2020). Audiencias vs desinformación. Una exploración durante la pandemia de covid-19 en Colombia. Estudos em Comunicação, 31, 35-51. http://ojs.labcom-ifp.ubi.pt/index. $\mathrm{php} / \mathrm{ec} / \mathrm{article} / \mathrm{download} / 825 / \mathrm{pdf}$

ConSalud (2020, diciembre 6). Asintomáticos y segunda ola: ¿hasta qué punto son "impulsores silenciosos" de la pandemia? https://www.consalud.es/pacientes/especial-coronavirus/ asintomaticos-ola-hasta-punto-impulsores-silenciosos-pandemia_88938_102.html 
De Moragas, M. (ed) (1986). Sociología de la comunicación de masas. II Estructura, funciones y efectos. Editorial Gustavo Gili.

Departamento Administrativo Nacional de Estadística - DANE (2018). Censo Nacional de Población y Vivienda: servicios públicos: internet. https://dane.maps.arcgis.com/apps/MapSeries/ index.html?appid=2749922ca5f8469db9990986c02b1

Eje21 (2020, septiembre 30). El consumo de televisión en 2020 sigue siendo más alto que en 2019. https://www.eje21.com.co/2020/09/el-consumo-de-television-en-2020-sigue-siendo-masalto-que-en-2019/

El Economista (2016, diciembre 1). Adjudicación de Canal Uno suma tercer canal privado a Colombia. https://www.eleconomista.com.mx/empresas/Adjudicacion-de-Canal-Uno-suma-tercercanal-privado-a-Colombia--20161201-0045.html

El Heraldo (2020, diciembre 16). El Heraldo lanza suscripciones digitales. https://www.elheraldo. co/region-caribe/el-heraldo-lanza-sus-suscripciones-digitales-780379

Gómez, M. (2013). ¿Crisis sanitarias o crisis mediáticas? Cuadernos de la Fundación Dr. Antonio Esteve, 25, 39-46. https://www.raco.cat/index.php/QuadernsFDAE/article/download/278649/366395

Kinnear, J. (2020, junio 25). Coronavirus: asymptomatic people can still develop lung damage. The Conversation. https://theconversation.com/coronavirus-asymptomatic-people-can-stilldevelop-lung-damage-141154

La República (2020, marzo 16). Claudia López declaró calamidad pública en Bogotá por aumento de casos de covid-19. https://www.larepublica.co/economia/claudia-lopez-aseguro-quela-primera-paciente-confirmada-con-covid-19-en-el-pais-ya-lo-supero-2978458

La Tercera (2020, marzo 7). ¿Por qué la OMS se niega a declarar pandemia por coronavirus? https://www.latercera.com/que-pasa/noticia/por-que-la-oms-se-niega-a-declarar-pandemia-porcoronavirus/S2QFX22ONJGAXMTQQI4X5XFLUE/

López, L. (1986). Introduccion a los medios de comunicación. Universidad Santo Tomás.

Lozano, J. (1996). Teoría e investigación de la comunicación de masas. Alhambra Mexicana.

Masip, P., Aran-Ramspott, S., Ruiz-Caballero, C., Suau, J., Almenar, E. \& Puertas-Graell, D. (2020). Consumo informativo y cobertura mediática durante el confinamiento por el Covid-19: sobreinformación, sesgo ideológico y sensacionalismo. El Profesional de la Información, 29(3). https://doi.org/10.3145/epi.2020.may.12

Ministerio de Salud y Protección Social (2020c, 31 de diciembre). Situación actual: nuevo coronavirus (covid-19). https://www.minsalud.gov.co/salud/publica/PET/PublishingImages/ covid-19\%20Colombia/311220_post_coronavirus_baja.jpg

Ministerio de Salud y Protección Social (2020d). Evolución de la afectación de municipios por covid-19. https://sig.sispro.gov.co/afectacionCovid/

Noticias ONU (2020, diciembre 29). 2020: el año de la pandemia de covid-19 que cerró el mundo. https://news.un.org/es/story/2020/12/1486082

Ortiz, G. \& López, D. (2002). La observación de medios en la construcción de una comunicación sostenible para Colombia. Palabra Clave, 7. https://palabraclave.unisabana.edu.co/index.php/ palabraclave/article/view/401/539 
Pan American Health Organization - PAHO (2020, febrero 28). Epidemiological Update Novel coronavirus (Covid-19). https://www.paho.org/hq/index.php?option=com docman\&view=download\&category_slug=coronavirus-epidemiological-alerts-andupdates\&alias $=51812$-28-february-2020-novel-coronavirus-covid-19-epidemiological-update$1 \&$ Itemid= $270 \&$ lang $=$ en

Potter, D. (2006). Manual de periodismo independiente. Programas de Información Internacional del Departamento de Estado de Estados Unidos de América. https://photos.state.gov/libraries/ amgov/30145/publications-spanish/handbook_journalism-sp.pdf

Presidencia de la República de Colombia (2020a, marzo 23). Gobierno Nacional expide el Decreto 457, mediante el cual se imparten instrucciones para el cumplimiento del Aislamiento Preventivo Obligatorio de 19 días en todo el territorio colombiano. https://id.presidencia.gov. co/Paginas/prensa/2020/Gobierno-Nacional-expide-Decreto-457-mediante-el-cual-imparteninstrucciones-para-cumplimiento-Aislamiento-Preventiv-200323.aspx

Presidencia de la República de Colombia (2020b, agosto 25). Decreto 1168 de 2020. https:// dapre.presidencia.gov.co/normativa/normativa/DECRETO\%201168\%20DEL\%2025\%20DE\%20 AGOSTO\%20DE\%202020.pdf

Puelles, V. et al. (2020). Multiorgan and Renal Tropism of SARS-CoV-2. The New England Journal of Medicine, 383, 590-592. https://www.nejm.org/doi/full/10.1056/NEJMc2011400

Reuters (2019, diciembre 31). Chinese officials investigate cause of pneumonia outbreak in Wuhan. https://www.reuters.com/article/us-china-health-pneumonia/chineseofficials-investigatecause-of-pneumonia-outbreak-in-wuhan-idUSKBN1YZ0GP

Reuters (2020a, mayo 13). 'This virus may never go away,' WHO says. https://www.reuters.com/ article/us-health-coronavirus-who-briefing-idUSKBN22P2IJ

Reuters (2020b, enero 17). Thailand finds second case of new Chinese virus, says no outbreak. https://www.reuters.com/article/china-health-pneumonia-thailand-idUSL4N29M1BL

Rodero, E. (2020). La radio: el medio que mejor se comporta en las crisis. Hábitos de escucha, consumo y percepción de los oyentes de radio durante el confinamiento por el covid-19. El profesional de la información, 29(3), 290-306. http://dx.doi.org/10.3145/ epi.2020.may.06

Shaman, J. \& Galanti, M. (2020, octubre 30). Will SARS-CoV-2 become endemic? Science, 370(6516), 527-529. https://science.sciencemag.org/content/370/6516/527/

Sotelo, D. (2020). Pandemias, información y medios: covid-19, un ejemplo a través de la crisis. Revista Medicina, 42(2), 143-146. http://revistamedicina.net/ojsanm/index.php/Medicina/article/ view/1531/1945

World Health Organization - WHO (2020a, enero 31). 2019-nCoV outbreak is an emergency of international concern. https://www.euro.who.int/en/health-topics/health-emergencies/ international-health-regulations/news/news/2020/2/2019-ncov-outbreak-is-an-emergency-ofinternational-concern

World Health Organization - WHO (2020b, marzo 11). Alocución de apertura del Director General de la OMS en la rueda de prensa sobre la covid-19 celebrada el 11 de marzo de 2020. https://www.who.int/es/director-general/speeches/detail/who-director-general-s-opening-remarksat-the-media-briefing-on-covid-19---11-march-2020 
World Health Organization - WHO (2020c, diciembre 29). Weekly epidemiological update - 29 December 2020. https://www.who.int/publications/m/item/weekly-epidemiological-update---29december-2020

World Health Organization - WHO (2020d, enero 13). WHO statement on novel coronavirus in Thailand. https://www.who.int/news/item/13-01-2020-who-statement-on-novel-coronavirus-inthailand

World Health Organization - WHO (2020e). Novel coronavirus (2019n-CoV) Situation Report13. https://www.who.int/docs/default-source/coronaviruse/ situation-reports/20200202-sitrep-13ncov-v3.pdf. 